\title{
An Afterword
}

\author{
Arthur B. Kennickell \\ Board of Governors of the Federal Reserve System (Ret.), Washington, DC, USA \\ E-mail: Arthur.Kennickell@gmail.com
}

I am very grateful for the remarks from (in order of appearance in this issue of the SJIAOS) Barry Johnson, Emmanuel Saez, Teresita Bascos-Deveza, Julia Lane, Catherine Haggerty, Steven Pedlow, Micah Sjoblom, Stephanie Eckman, Brian Bucks, Steven Heeringa, Olympia Bover, Donald Rubin, Sébastien Perez-Duarte, Carlos Sanchez-Muñoz, Pirmin Fessler, Martin Schüz and Andrea Brandolini. Because I am a modest person, I also blush at many of their remarks. I wish I could compose an anthem for each of them. There is little for me to say in the way of a traditional rejoinder, as their writings speak well on their own. But I would like to amplify a few of the points raised in the comments.

Both Barry Johnson and Emmanuel Saez note the importance of clarifying the relationship between income and wealth. As I hope is clear from my "Lining Up" paper, I am very supportive of this idea. Such work is important not just for understanding that relationship, but also for the possibility of making better projections of wealth from administrative data and developing a more robust support for the SCF and other wealth surveys in characterizing the wealth distribution. I expect progress here will require a serious commitment not just to working through the privacy and legal constraints, but also to understanding more deeply the broad set of measurement processes underlying both the survey and the administrative data. There are many conceptual issues and many issues related to survey sampling and response to be resolved. It is not enough to speak hypothetically. In addition, I expect that observed rates of return, which Barry notes are lower on average for those with high income, will show substantial cross-sectional and time series heterogeneity even within subgroups of the wealth distribution. If so, addressing such variability will be important for making reliable projections gauged with an appropriate measure of statistical confidence.
Surveys obviously require participation by respondents, both in gaining initial cooperation and in providing meaningful answers throughout the interview. The interviewer is central to achieving this goal, as stressed in the comments of Terry Deveza, Julia Lane, Catherine Haggerty, Steven Pedlow, Micah Sjoblom, Stephanie Eckman, Brian Bucks and Steven Heeringa. We have developed systems and other frameworks in order to gain a better understanding of the patterns of behavior of interviewers and respondents in the field, and devised compensating statistical adjustments. But despite the many theories and studies, our knowledge about the engagement process is still limited. Because surveys by their very nature require more than an understanding of "average" behavior, we must continue to try to crack open the large amount of unexplained heterogeneity that remains. There is still much we can learn, especially from interviewers. We should also try, to the limits of what we do know, to inform and support interviewers, who have by far the most difficult job in a field survey. Developing a clear channel to make that communication is not easy, as both Brian Bucks and Olympia Bover emphasize.

As Steve Heeringa also pointed out, one feature of the SCF is its relentless pursuit of response to the last potentially willing respondent - something that most other surveys are unable to do. Variation across waves of a survey in the "cut-off point" for effort applied to achieve response can have serious effects on estimates. For the SCF, the approach to consistently relentless pursuit of respondents may matter especially for the characterizing the highly skewed wealth distribution. Work by Steve and his colleagues on responsive design is one promising way to bring a sufficiently controlled framework to address this problem and I am hopeful that it will ultimately be important tool for guiding the terminal field efforts of the SCF. 
Thanks to Don Rubin for his thoughts on the history of multiple imputation (MI), in which he played the most central role. It is an impressive history. I think he may have been misled by the 1998 date on the date on the paper he was sent by the editor to serve as an anchor for his comments. That paper on MI, which is included in this issue, is a backward-looking view of how far the work on MI had come for the SCF at that point. In fact, the first implementation was for the 1989 survey, and work on developing the model framework began a year earlier. I was very lucky then to be able to present (nervously) my model to both Don and to Rod Little, who were wonderfully helpful and supportive. So tight were computer resources at the time that the model could only be run on a special work station and the total running time through all iterations was about 6 months - without taking account of the substantial additional time needed to address the errors and complicated empirical constraints that emerged. By the time of the 1998 paper, the IT constraints had largely evaporated. It was already possible to undertake work on broad data simulation using MI, an idea Don had proposed earlier to address disclosure concerns. Early on, MI in the SCF met with strong initial resistance from users, who saw no need for it. But by 1998, resistance to MI was beginning to recede, as Don noted from the other MI work undertaken by then. Now, MI is covered in econometrics text books and work proceeds widely on new applications and modifications. This is success.

Sébastien Perez-Duarte and Carlos Sanchez-Muñoz both focus most closely on the Household Finance and Consumption Survey (HFCS), which is coordinated by the European Central Bank and implemented at the level of the member national central banks. As I noted in my interview in this issue, it was a great day for me personally and professionally when I received a call from Reint Gropp asking me to participate in a group to develop a proposal for what became the HFCS. I cannot speak highly enough of the commitment, intelligence, collegiality and friendship I have experienced among the participants throughout the work to develop, implement and analyze this survey. Of course, this does not mean it has always been easy. But confronting the state of the art with the differences of opinions and the necessary constraints has led to an excellent survey with a strong structure to support its healthy evolution for the long run.

I am especially humbled by the comments of Pirmin Fessler and Martin Schüz. While I do think they see my aspirations, they both much too kindly shade out the ways I fall short. Like everyone else and everything, I am a work in progress - continuously trying to improve, I hope, as long as I can. The issues they raise independently of assessing the distribution of wealth are ones I wish were more broadly recognized. Most data do not "speak for themselves" but require some framework to make results visible. But overly strong attachment to a single point of view often risks missing important deeper relationships. Among other things, wealth does not always mean the same thing, depending on the holder and the circumstances. Wealth may only appear to be a one-dimensional variable.

Finally, I resonate strongly with the questions raised by Andrea Brandolini in his discussion. He gives me the opportunity to speak on a point that underlies my thinking in the papers presented here, but that may not be obvious. There are most frequently many nonnegligible sources of uncertainty in acts of economic measurement. But ultimately the reason for collecting data is to be able to address questions resting on empirical relationships or distributions. For that, we do not want to undertake work with the prospect of being lost in nebulous uncertainty about why we might not believe the results. There needs to be a limit to how far we take skepticism and caution in interpreting scientifically collected data. Otherwise we would have no basis on which to learn anything positive at all. I would, however, take those limits further before executing a survey than I would afterwards. I see an obligation before a survey is executed to think as hard as possible about how to take earlier lessons into account to prevent, or at least bound, the intensity of "known" problems that might undermine analysis. After a survey is completed, honest accounting and reporting for significant problems and consistency of transparency about remedial methods are essential. But it not enough to take the "easy" solution of providing the information and allowing the user to decide how to condition on the design, execution and processing of the survey. An honest attempt must also be taken to organize such information and give examples of how it might be appropriately used. For their part, users must face the sometimes annoying fact that there is no substitute for thinking about what they want to do and what might matter for the sake of their analyses.

In a repeated survey, it is also critical to repeat the "Deming cycle" - to take into account what has been learned in coping with deficiencies detected and from interactions with users of the data in order to develop a strategy for the next iteration. If we are careful - 
and lucky - the level of resulting improvement in measurement will be greater than the pressures of entropy. Given the complexities of the world, I strongly believe a survey that does not continuously attempt to improve will ultimately be rendered irrelevant. Measurement is not for the faint of heart, as I know all the commenters know all too well!
Thanks again to my friends here who have provided comments as well as to the many other people who shared enough of their thoughts with me earlier that I would have something to say in this special issue. I hope there will be motivation in the work gathered here for others to go further in serving the public interest through careful measurement and research. Thanks also to you, the reader, for your attention. 